University of Nebraska - Lincoln

DigitalCommons@University of Nebraska - Lincoln

$10-2011$

\title{
Optic Disc Edema, Globe Flattening, Choroidal Folds, and Hyperopic Shifts Observed in Astronauts after Long-duration Space Flight
}

\author{
Thomas H. Mader \\ Alaska Native Medical Center, tmader@acsalaska.net \\ C. Robert Gibson \\ Coastal Eye Associates \\ Anastas F. Pass \\ University of Houston \\ Larry A. Kramer \\ University of Texas Health Science Center \\ Andrew G. Lee \\ The Methodist Hospital \\ See next page for additional authors \\ Follow this and additional works at: https://digitalcommons.unl.edu/nasapub \\ Part of the Physical Sciences and Mathematics Commons
}

Mader, Thomas H.; Gibson, C. Robert; Pass, Anastas F.; Kramer, Larry A.; Lee, Andrew G.; Fogarty, Jennifer; Tarver, William J.; Dervay, Joseph P.; Hamilton, Douglas R.; Sargsyan, Ashot; Phillips, John L.; Tran, Duc; Lipsky, William; Choi, Jung; Stern, Claudia; Kuyumjian, Raffi; and Polk, James D., "Optic Disc Edema, Globe Flattening, Choroidal Folds, and Hyperopic Shifts Observed in Astronauts after Long-duration Space Flight" (2011). NASA Publications. 69.

https://digitalcommons.unl.edu/nasapub/69

This Article is brought to you for free and open access by the National Aeronautics and Space Administration at DigitalCommons@University of Nebraska - Lincoln. It has been accepted for inclusion in NASA Publications by an authorized administrator of DigitalCommons@University of Nebraska - Lincoln. 


\section{Authors}

Thomas H. Mader, C. Robert Gibson, Anastas F. Pass, Larry A. Kramer, Andrew G. Lee, Jennifer Fogarty, William J. Tarver, Joseph P. Dervay, Douglas R. Hamilton, Ashot Sargsyan, John L. Phillips, Duc Tran, William Lipsky, Jung Choi, Claudia Stern, Raffi Kuyumjian, and James D. Polk 


\section{Optic Disc Edema, Globe Flattening, Choroidal Folds, and Hyperopic Shifts Observed in Astronauts after Long-duration Space Flight}

Thomas H. Mader, MD, ${ }^{1}$ C. Robert Gibson, OD, ${ }^{2}$ Anastas F. Pass, OD, JD, ${ }^{3}$ Larry A. Kramer, MD, ${ }^{4}$ Andrew G. Lee, MD, Jennifer Fogarty, PhD, ${ }^{6}$ William J. Tarver, MD, ${ }^{6}$ Joseph P. Dervay, MD, ${ }^{6}$ Douglas R. Hamilton, MD, PhD, ${ }^{7}$ Ashot Sargsyan, MD, ${ }^{7}$ John L. Phillips, PhD, ${ }^{8}$ Duc Tran, DO, ${ }^{2}$ William Lipsky, MD, ${ }^{2}$ Jung Choi, OD, ${ }^{2}$ Claudia Stern, MD, PhD, ${ }^{9}$ Raffi Kuyumjian, MD ${ }^{10}$ James D. Polk, DO ${ }^{6}$

Purpose: To describe the history, clinical findings, and possible etiologies of ophthalmic findings discovered in 7 astronauts after long-duration space flight, and document vision changes in approximately 300 additional astronauts.

Design: Retrospective, observational examination of ophthalmic findings in 7 astronauts and analysis of postflight questionnaires regarding in-flight vision changes in approximately 300 additional astronauts.

Participants: Seven astronauts with ophthalmic anomalies upon return from long-duration space missions to the International Space Station and 300 additional astronauts who completed postflight questionnaires regarding in-flight vision changes.

Methods: Before and after long-duration space flight, all 7 subjects underwent complete eye examinations, including cycloplegic and/or manifest refraction and fundus photography. Six underwent postmission optical coherence tomography (OCT) and magnetic resonance imaging (MRI); 4 had lumbar punctures (LP). Approximately 300 astronauts were queried regarding visual changes during space missions.

Main Outcome Measures: Refractive change, fundus photograph examination, retina OCT, orbital MRI, LP opening pressures, and examination of visual acuity data.

Results: After 6 months of space flight, 7 astronauts had ophthalmic findings, consisting of disc edema in 5 , globe flattening in 5 , choroidal folds in 5 , cotton wool spots (CWS) in 3 , nerve fiber layer thickening by OCT in 6 , and decreased near vision in 6 astronauts. Five of 7 with near vision complaints had a hyperopic shift $\geq+0.50$ diopters $(\mathrm{D})$ between pre/postmission spherical equivalent refraction in 1 or both eyes (range, +0.50 to $+1.75 \mathrm{D}$ ). These 5 showed globe flattening on MRI. Lumbar punctures performed in the 4 with disc edema documented opening pressures of $22,21,28$, and $28.5 \mathrm{~cm} \mathrm{H}_{2} \mathrm{O}$ performed $60,19,12$, and 57 days postmission, respectively. The 300 postflight questionnaires documented that approximately $29 \%$ and $60 \%$ of astronauts on short and long-duration missions, respectively, experienced a degradation in distant and near visual acuity. Some of these vision changes remain unresolved years after flight.

Conclusions: We hypothesize that the optic nerve and ocular changes we describe may result from cephalad fluid shifts brought about by prolonged microgravity exposure. The findings we report may represent parts of a spectrum of ocular and cerebral responses to extended microgravity exposure.

Financial Disclosure(s): The authors have no proprietary or commercial interest in any of the materials discussed in this article. Ophthalmology 2011;118:2058-2069 () 2011 by the American Academy of Ophthalmology.

Physiologic and pathologic changes associated with the microgravity environment have been studied extensively. However, the effect of this environment on the eye and brain is largely unknown. Over the last several years, the National Aeronautics and Space Administration's (NASA) Space Medicine Division has documented astronauts presenting with varying degrees of disc edema, globe flattening, choroidal folds, and hyperopic shifts after long-duration space flight. The similarities of the setting and clinical features of these patients suggests a common etiology inherent to the microgravity environment. Because of the paucity of in-flight data, the specific cause of these disorders remains obscure. The authors propose that these findings may represent manifestations of a pathologic process related to ocular, optic nerve $(\mathrm{ON})$, or perhaps intracranial cephalad fluid shifts experienced during microgravity exposure. To 


\section{Mader et al - Eye Changes after Long-duration Space Flight}

our knowledge, this is the first published report documenting ophthalmic anomalies in astronauts or cosmonauts during or after space flight.

\section{Subjects and Methods}

A postflight survey of approximately 300 astronauts, some of whom were repeat flyers, revealed that vision changes were commonly observed during and after long-duration space missions. Since 1989, as part of the postflight eye examination, astronauts were queried as to whether they perceived a subjective improvement or degradation in distant or near vision (none, mild, moderate, or severe) during their short- and long-duration missions. Prompted by persistent reports of vision changes, NASA began a stepwise operational process to determine the etiology. Several ophthalmic procedures were initiated on astronauts, including dilated fundus examinations with binocular ophthalmoscopy, cycloplegic refraction, optical coherence tomography (OCT), magnetic resonance imaging (MRI) of orbits, and fundus photos of astronauts before and after space missions.

Space flight causes bone loss. As a countermeasure, it is recommended that all astronauts take 800 international units (IU) of vitamin D supplements daily during short- and long-duration space flights. Unless otherwise stated, the past medical history of all 7 astronauts was negative for systemic hypertension, connective tissue disorders, iron deficiency, diabetes mellitus, or renal disease. Again, unless stated otherwise, none of our subjects had ever used any medication that could produce increased intracranial pressure (ICP); (e.g., vitamin A, tetracycline, corticosteroids, or nalidixic acid.)

The NASA Space Medicine Division approves of the use of this routinely acquired and not attributable data to be used in this manner. These data are acquired under occupational surveillance and their use in this article is permitted under governance 10 Health Information Management System.

\section{Results}

After approximately 6 months of continuous orbital flight, 7 astronauts (all male; age 50.2 \pm 4.2 years) were documented to have findings as summarized in Table 1 . Table 2 is a summary of data from postflight questionnaires completed by approximately 300 astronauts after their short- and long-duration space missions. Approximately $23 \%$ of the short-duration and $48 \%$ of the longduration mission astronauts complained of near vision difficulties.

\section{Case Reports}

\section{Case 1}

This astronaut's preflight manifest refraction at 90 days before launch was: right eye, -1.50 sphere and left eye, -2.25 $-0.25 \times 135$, with a +1.50 add. He was correctable to $20 / 20$ in each eye and his dilated eye examination and fundus photos were normal. The only medication he used was promethazine for space adaptation syndrome. He noticed a marked decrease in near visual acuity starting about 6 weeks into the mission that persisted without progression for the remainder of the flight. At no time did he report headaches, transient visual obscurations, pulsatile tinnitus, or diplopia. Carbon dioxide levels were at normal operating levels $<5 \mathrm{mmHg}$ during the entire mission. Oxygen levels were also normal at 160 to $170 \mathrm{mmHg}(21 \%$
$23 \%$ ), the cabin pressure was steady at 735 to $765 \mathrm{mmHg}$, and there were no toxic fume exposures.

Nineteen days after return to Earth, his visual acuity was correctable to $20 / 20$ in both eyes with a manifest refraction of $-1.25-0.25 \times 005$ in the right eye and $-2.50-0.25 \times 160$ in the left, with a +2.00 add. He never at any time experienced losses in subjective best-corrected visual acuity, stereopsis, or color vision. His fundus examination revealed choroidal folds inferior to the optic disc (right eye) and a single cotton wool spot (CWS) in the inferior arcade (right eye; Fig 1, available online at http:// aaojournal.org). The acquired choroidal folds gradually improved, but were still present in fundus photographs taken 3 years postflight. The left eye examination was normal. There was no documented evidence of optic disc edema in either eye. Brain MRI, lumbar puncture (LP), and OCT were not performed preflight or postflight on this astronaut. It should be noted that choroidal folds are still present (right eye only) on OCT performed $>5$ years postflight (Fig 1, bottom).

\section{Case 2}

This astronaut's manifest refraction 120 days before the mission was +0.75 sphere on the right and $+0.75-0.25 \times 165$ on the left; his visual acuity was correctable in each eye to $20 / 15$. He had $\mathrm{a}+2.25$ bifocal add in both lenses. His dilated fundus examination was normal and documented with preflight fundus photos. During the mission, he took a multivitamin daily, potassium citrate (part of an experiment), and zolpidem occasionally for sleep induction.

During the first 2 months in orbit, he had no visual complaints and could see the Earth clearly without glasses. Approximately 3 months into the mission, he noted that he could now only see the Earth clearly while looking through the lower portion of his progressive reading glasses. This change persisted for the remainder of the mission without noticeable improvement or progression. He complained of no transient visual obscurations, headaches, diplopia, pulsatile tinnitus, or vision changes during eye movement. Carbon dioxide, cabin pressure, and oxygen were at normal operating levels during the mission, and he was not exposed to any toxic substances.

Upon return to Earth, the vision disturbances observed during microgravity continued. Twenty-one days after the mission, his visual acuity was correctable to $20 / 20$ with a manifest refraction of +2.00 sphere on the right and $+2.00-0.50 \times 140$ on the left. Over the next several months, he noted a gradual but incomplete improvement in vision. His refraction 232 days postflight was +1.50 sphere on the right and $+1.50-0.25 \times 170$ on the left. He never at any time experienced losses in subjective bestcorrected visual acuity, stereopsis, or color vision. Twenty-one days after his return to Earth, a fundus examination was performed, which documented mild bilateral nasal optic disc edema (grade 1, Frisén scale), right greater than left, and choroidal folds (Fig 2, available online at http://aaojournal.org). Fluorescein angiography confirmed the choroidal folds but showed no other abnormalities. Magnetic resonance angiography and magnetic resonance venogram were normal. The OCT confirmed the increased nerve fiber layer (NFL) thickening consistent with optic disc edema nasally and demonstrated a normal macula. An MRI of the brain and orbits with and without gadolinium contrast, performed 23 days after return, documented mildly dilated ON sheaths and flattening of the posterior globes bilaterally. A CWS was present in the left eye $1 \frac{1}{2}$ disc diameters inferior temporal to the disc and just inside the inferior arcades. Two months after return to Earth, a LP documented a borderline opening pressure of $22 \mathrm{~cm} \mathrm{H}_{2} \mathrm{O}$ with normal cerebral spinal fluid (CSF) composition. 
Table 1. Neuroophthalmic Changes in Astronauts

\begin{tabular}{|c|c|c|c|c|c|c|}
\hline \multirow{2}{*}{$\begin{array}{l}\text { ISS } \\
\text { Crew } \\
\text { Member }\end{array}$} & \multirow{2}{*}{$\begin{array}{l}\text { Mission } \\
\text { Duration } \\
(\text { mos })\end{array}$} & \multicolumn{2}{|c|}{ Refractive Change } & \multicolumn{2}{|c|}{$\begin{array}{l}\text { Intraocular Pressure } \\
(\mathrm{mmHg})\end{array}$} & \multirow{2}{*}{$\begin{array}{c}\text { Fundoscopic Examination } \\
\text { Postflight }\end{array}$} \\
\hline & & Preflight & Postflight & Preflight & Postflight & \\
\hline 1 & 6 & $\begin{array}{l}\text { OD: }-1.50 \text { sph } \\
\text { OS: }-2.25-0.25 \times 135\end{array}$ & $\begin{array}{l}\text { OD: }-1.25-0.25 \times 005 \\
\text { OS: }-2.50-0.25 \times 160\end{array}$ & $15 \mathrm{OU}$ & $10 \mathrm{OU}$ & $\begin{array}{l}\text { Choroidal folds OD } \\
\text { Cotton wool spot OD }\end{array}$ \\
\hline 2 & 6 & $\begin{array}{l}\text { OD: }+0.75 \text { sph } \\
\text { OS: }+0.75-0.25 \times 165\end{array}$ & $\begin{array}{l}\text { OD: }+2.00 \mathrm{sph} \\
\text { OS: }+2.00-0.50 \times 140\end{array}$ & $14 \mathrm{OU}$ & $14 \mathrm{OU}$ & $\begin{array}{l}\text { Bilateral disc edema OD }>\text { OS } \\
\text { Choroidal folds } \\
\text { OD }>\text { OS } \\
\text { Cotton wool spot OS }\end{array}$ \\
\hline 3 & 6 & $\begin{array}{l}\text { OD: }-0.50 \mathrm{sph} \\
\text { OS: }-0.25 \mathrm{sph}\end{array}$ & $\begin{array}{l}\text { OD: Plano } \\
\text { OS: Plano }\end{array}$ & $10 \mathrm{OU}$ & $10 \mathrm{OU}$ & $\begin{array}{l}\text { Bilateral disc edema OD }>\text { OS } \\
\text { Small hemorrhage OD }\end{array}$ \\
\hline 4 & 6 & $\begin{array}{l}\text { OD: }-0.75-0.50 \times 100 \\
\text { OS: plano }-0.50 \times 090\end{array}$ & $\begin{array}{l}\text { OD: }+0.75-0.50 \times 105 \\
\text { OS: }+0.75-0.75 \times 090\end{array}$ & $15 / 13$ & $11 / 10$ & $\begin{array}{l}\text { Disc edema OD } \\
\text { Choroidal folds OD }\end{array}$ \\
\hline 5 & 6 & $\begin{array}{l}\text { OD: }-5.75-1.25 \times 010 \\
\text { OS: }-5.00-1.50 \times 180\end{array}$ & $\begin{array}{l}\text { OD: }-5.00-1.50 \times 015 \\
\text { OS: }-4.75-1.75 \times 170\end{array}$ & $14 / 12$ & $14 / 12$ & Normal \\
\hline 6 & 6 & $\begin{array}{l}\text { OD: }+0.25 \mathrm{sph} \\
\text { OS: }+0.25-0.50 \times 152\end{array}$ & $\begin{array}{l}\text { OD: }+2.00-0.50 \times 028 \\
\text { OS: }+1.00 \mathrm{sph}\end{array}$ & $14 \mathrm{OU}$ & $14 \mathrm{OU}$ & $\begin{array}{l}\text { Disc edema OD } \\
\text { Cotton wool spot OS }\end{array}$ \\
\hline 7 & 6 & $\begin{array}{l}\text { OD: }+1.25 \mathrm{sph} \\
\text { OS: }+1.25 \mathrm{sph}\end{array}$ & $\begin{array}{l}\text { OD: }+2.75 \mathrm{sph} \\
\text { OS: }+2.50 \mathrm{sph}\end{array}$ & $16 \mathrm{OU}$ & $12 / 14$ & $\begin{array}{l}\text { Disc edema OU } \\
\text { Choroidal folds OD > OS }\end{array}$ \\
\hline
\end{tabular}

$\mathrm{CSF}=$ cerebral spinal fluid; MRI = magnetic resonance imaging; NFL = retinal nerve fiber layer; OCT $=$ optical coherence tomography; $\mathrm{OD}=$ right; Disc edema was graded with the modified Frisén scale.

\section{Case 3}

Preflight cycloplegic refraction was -0.50 sphere in the right eye and -0.25 sphere in the left eye, and correctable in each eye to 20/15. His dilated eye examination and fundus photos were normal. His past medical history included mild systemic hypertension controlled with lisinopril (10 mg) and dyslipidemia, wellcontrolled on atorvastatin $(10 \mathrm{mg})$. During the mission, he also took promethazine for 2 days to treat symptoms of space adaptation syndrome, and a multivitamin (Centrum Silver, Pfizer, New York, New York), but no additional vitamin A analogs. He reported no changes in visual acuity during the mission with no complaints of headaches, transient visual obscurations, diplopia, or pulsatile tinnitus. Carbon dioxide and oxygen levels were at acceptable levels during the mission, and he had no toxic exposures. No ocular issues were reported by the astronaut at landing.

Three days after return to Earth, he was correctable to $20 / 20$ both eyes with a cycloplegic refraction of plano in each eye. Fundus examination revealed bilateral, asymmetrical disc edema (right eye, grade 3; left eye, grade 1; Fig 3). There was no evidence of choroidal folds or CWS. A small hemorrhage was observed inferior to the optic disc in the right eye. At 10 days postlanding, an MRI of the brain and orbits was normal except for ON thickening in the right eye greater than the left eye (Fig 4; available online at http://aaojournal.org). There was no posterior globe flattening. A magnetic resonance venogram showed no evidence for cerebral venous sinus thrombosis. On OCT, there was marked NFL thickening (right eye more than the left eye), consistent with optic disc edema (Fig 5; available online at http://aaojournal.org.) At 19 days after return to Earth, an LP documented a mildly elevated opening pressure of $21 \mathrm{~cm} \mathrm{H}_{2} \mathrm{O}$ with normal CSF composition.

\section{Case 4}

Preflight eye examination revealed a cycloplegic refraction of $-0.75-0.50 \times 100$ on the right and plano $-0.50 \times 090$ on the left, correctable in each eye to $20 / 15$. He had a reading add of +2.00 both eyes. His preflight dilated eye examination and fundus photos were normal. During the mission, he used a topical corticosteroid and oral ketoconazole for a facial rash and promethazine for 1 day to treat symptoms of space adaptation syndrome. During the mission, this astronaut took a 6-day tapering dose of methylprednisolone followed by prednisone $40 \mathrm{mg} / \mathrm{d}$ for 1 week to treat an allergic skin condition.

Approximately 6 to 8 weeks into the mission, he reported a progressive decrease in near visual acuity in his right eye, followed by a mild, "vertical football"-shaped scotoma located $15^{\circ}$ to $30^{\circ}$ into his right temporal field of vision. The scotoma seemed to be fixed and translucent, and was stable for the remainder of the mission. He never complained of transient visual obscurations, headaches, diplopia, pulsatile tinnitus, or vision changes during eye movement. International Space Station (ISS) cabin pressure, carbon dioxide, and oxygen levels were reported to be at normal operating levels during the mission. During the mission, one of his fellow astronauts also complained of decreased near visual acuity (case 5). Five months into the mission, a video funduscopic imaging system was used to obtain retinal and $\mathrm{ON}$ images that were downlinked to NASA personnel for ophthalmologic consultation. These images allowed experts on the ground to diagnose mild optic disc edema in the right eye (Fig 6). The temporal location and shape of the reported scotoma was thought to be consistent with disc edema (i.e., enlarged blind spot).

His vision changes persisted upon return to Earth. Ten days postflight, his visual acuity was correctable to $20 / 15$ with a cycloplegic refraction of $+0.75-0.50 \times 105$ on the right and to +0.75 $-0.75 \times 090$ on the left. He never experienced losses in subjective best-corrected acuity, color vision, or stereopsis. Fundus examination revealed mild, nasal disc edema (grade 1, Frisén scale) of the right eye with choroidal folds extending from the disc into the macula (Fig 6). On OCT, optic disc edema and choroidal folds were confirmed (Fig 7; available online at http://aaojournal.org). An MRI of the brain and orbits performed 30 days postflight documented severely dilated ON sheaths (right greater than left), flattening of the posterior globes (right greater than left), and thickened tortuous ONs (Fig 8). An intracranial magnetic reso- 
after Long-duration Space Flight

\begin{tabular}{|c|c|c|c|c|}
\hline Disc Edema (Frisén) & OCT Postflight & Eye MRI Postflight & $\begin{array}{l}\text { Globe } \\
\text { Flattening }\end{array}$ & $\begin{array}{c}\text { CSF Pressure } \\
\text { Postflight }\left(\mathrm{cmH}_{2} \mathrm{O}\right)\end{array}$ \\
\hline No disc edema & $\begin{array}{l}\text { Choroidal folds still visible inferior to } \\
\text { the OD disc }(\mathrm{R}+>5 \mathrm{yrs})\end{array}$ & MRI not performed & Not assessed & Not measured \\
\hline Grade $1 \mathrm{OD}$ and $\mathrm{OS}$ & NFL thickening $\mathrm{c} / \mathrm{w}$ disc edema & $\begin{array}{l}\text { Optic nerve sheath distension } \\
\text { OD and OS }\end{array}$ & $\mathrm{OD}$ and $\mathrm{OS}$ & $\begin{array}{l}\text { Elevated } \\
22 \text { at } R+66 \text { days; } \\
26 \text { at } R+17 \text { months; } \\
22 \text { at } R+19 \text { months }\end{array}$ \\
\hline $\begin{array}{l}\text { Grade } 3 \text { OD } \\
\text { Grade } 1 \text { OS }\end{array}$ & $\begin{array}{l}\text { Severe NFL thickening OD }>\text { OS } \\
\text { c/w Disc edema }\end{array}$ & $\begin{array}{l}\text { Optic nerve sheath distension } \\
\text { OD }\end{array}$ & None observed & $\begin{array}{l}\text { Elevated } \\
21 \text { at } R+19 \text { days }\end{array}$ \\
\hline Grade 1 OD & $\begin{array}{l}\text { Mild NFL thickening OD }>\text { OS c/w } \\
\text { disc edema } \\
\text { Choroidal folds OD }\end{array}$ & $\begin{array}{l}\text { Optic nerve sheath distension } \\
\text { and tortuous optic nerves } \\
\text { OD > OS }\end{array}$ & OD $>$ OS & $\begin{array}{l}\text { Elevated } \\
28.5 \text { at } R+57 \text { days }\end{array}$ \\
\hline No disc edema & $\begin{array}{l}\text { Subclinical disc edema } \\
\text { Mild/moderate NFL thickening OD }\end{array}$ & $\begin{array}{l}\text { Optic nerve sheath distension } \\
\text { and tortuous optic nerves }\end{array}$ & $\mathrm{OD}$ and $\mathrm{OS}$ & Not measured \\
\hline Grade 1 OD & $\begin{array}{l}\text { Mild NFL thickening c/w disc edema } \\
\text { Choroidal folds OD }\end{array}$ & $\begin{array}{l}\text { Optic nerve sheath distension } \\
\text { OD }>\text { OS }\end{array}$ & $\mathrm{OD}>\mathrm{OS}$ & Not measured \\
\hline Grade $1 \mathrm{OD}$ and $\mathrm{OS}$ & $\begin{array}{l}\text { Moderate NFL thickening } \mathrm{c} / \mathrm{w} \text { disc } \\
\text { edema OD and OS } \\
\text { Choroidal folds OD and OS }\end{array}$ & $\begin{array}{l}\text { Optic nerve sheath distension } \\
\text { OD and OS }\end{array}$ & $\mathrm{OD}$ and $\mathrm{OS}$ & $\begin{array}{l}\text { Elevated } \\
28 \text { at } R+12 \text { days }\end{array}$ \\
\hline
\end{tabular}

OS $=$ left; $\mathrm{OU}=$ both eyes; $\mathrm{R}+=$ return to Earth (eg, $\mathrm{R}+19$ is 19 days after return to Earth); sph = sphere.

nance venogram and magnetic resonance angiography subsequently obtained showed no abnormalities. Fifty-seven days after return to Earth, an LP documented an elevated opening pressure of $28.5 \mathrm{~cm} \mathrm{H}_{2} \mathrm{O}$ with normal CSF composition.

\section{Case 5}

A preflight eye examination revealed a cycloplegic refraction of $-5.75-1.25 \times 010$ on the right, and $-5.00-1.50 \times 180$ on the left, correctable in each eye to $20 / 20$. His reading add was +1.75 both eyes. Dilated eye examination and fundus photos were normal. During the mission, he took promethazine for a few days to treat symptoms of space adaptation syndrome. Three weeks after launch, he reported a moderate decrease in near visual acuity, right eye greater than left, which persisted for the remainder of the mission without change. He never complained of headaches, transient visual obscurations, diplopia, pulsatile tinnitus, or other vision changes. Carbon dioxide, oxygen, and ISS cabin pressure were at acceptable levels during the mission. One fellow crewmember complained of visual changes (case 4).

Upon return to Earth, he noted persistence of the vision changes he observed in space. Postflight visual acuity was correctable to $20 / 20$ both eyes with a manifest and cycloplegic refraction of $-5.00-1.50 \times 015$ on the right and $-4.75-1.75 \times 170$ on the left and a reading add of +2.25 both eyes. He never experienced losses in subjective best-corrected acuity, color vision, or stereopsis. His fundus examination was normal with no evidence of disc edema or choroidal folds. However, MRI of the brain and orbits, performed 8 days after return, documented bilateral posterior globe flattening, distended ON sheaths, and tortuous ONs. The ONs were not thickened. On OCT, significant NFL thickening in the right eye was shown relative to preflight values and a normal macula (Fig 9; available online at http://aaojournal.org). An LP was not performed.

\section{Case 6}

Preflight eye examination documented a cycloplegic refraction of +0.25 sphere on the right and $+0.25-0.50 \times 152$ on the left, correctable in each eye to $20 / 15$ with a reading add of +1.25 . His dilated eye examination and fundus photos were normal. During the mission he took promethazine for 1 to 2 days to treat symptoms of space adaptation syndrome. He reported no significant changes in visual acuity during the mission and never complained of transient visual obscurations, diplopia, pulsatile tinnitus, or other vision changes. Carbon dioxide, oxygen, and cabin pressure levels were reported to be within acceptable levels throughout the mission. He was not exposed to any toxic substances.

Table 2. Reported In-Flight Subjective Visual Changes and Postflight Refraction Changes of National Aeronautics and Space Administration Astronauts (Not Including International Partners) from 1989 to 2009

\begin{tabular}{lcc}
\hline Description & Shuttle \% (n) & ISS-Long Duration \% (n) \\
\hline Decreased DVA & & \\
Total (n) & 581 & 44 \\
None & $93.5(543)$ & $88.1(39)$ \\
Mild & $5.7(33)$ & $2.4(1)$ \\
Moderate & $0.9(5)$ & $4.8(2)$ \\
Severe & $0(0)$ & $4.8(2)$ \\
Decreased NVA & & \\
Total (n) & 584 & 44 \\
None & $76.7(448)$ & $13.6(23)$ \\
Mild & $17.6(103)$ & $27.3(12)$ \\
Moderate & $5.5(32)$ & $6.8(3)$ \\
Severe & $0.2(1)$ & \\
Refraction change & & 44 \\
Total (n) & 587 & $65.9(29)$ \\
None & $88.9(522)$ & $25.0(11)$ \\
Mild & $9.2(54)$ & $2.3(1)$ \\
Moderate & $1.9(11)$ & $6.8(3)$ \\
Severe & $0(0)$ &
\end{tabular}

DVA $=$ distance visual acuity; ISS $=$ International Space Station; NVA $=$ near visual acuity.

Source: Lifetime Surveillance of Astronaut Health (LSAH) Program, NASA Johnson Space Center. 


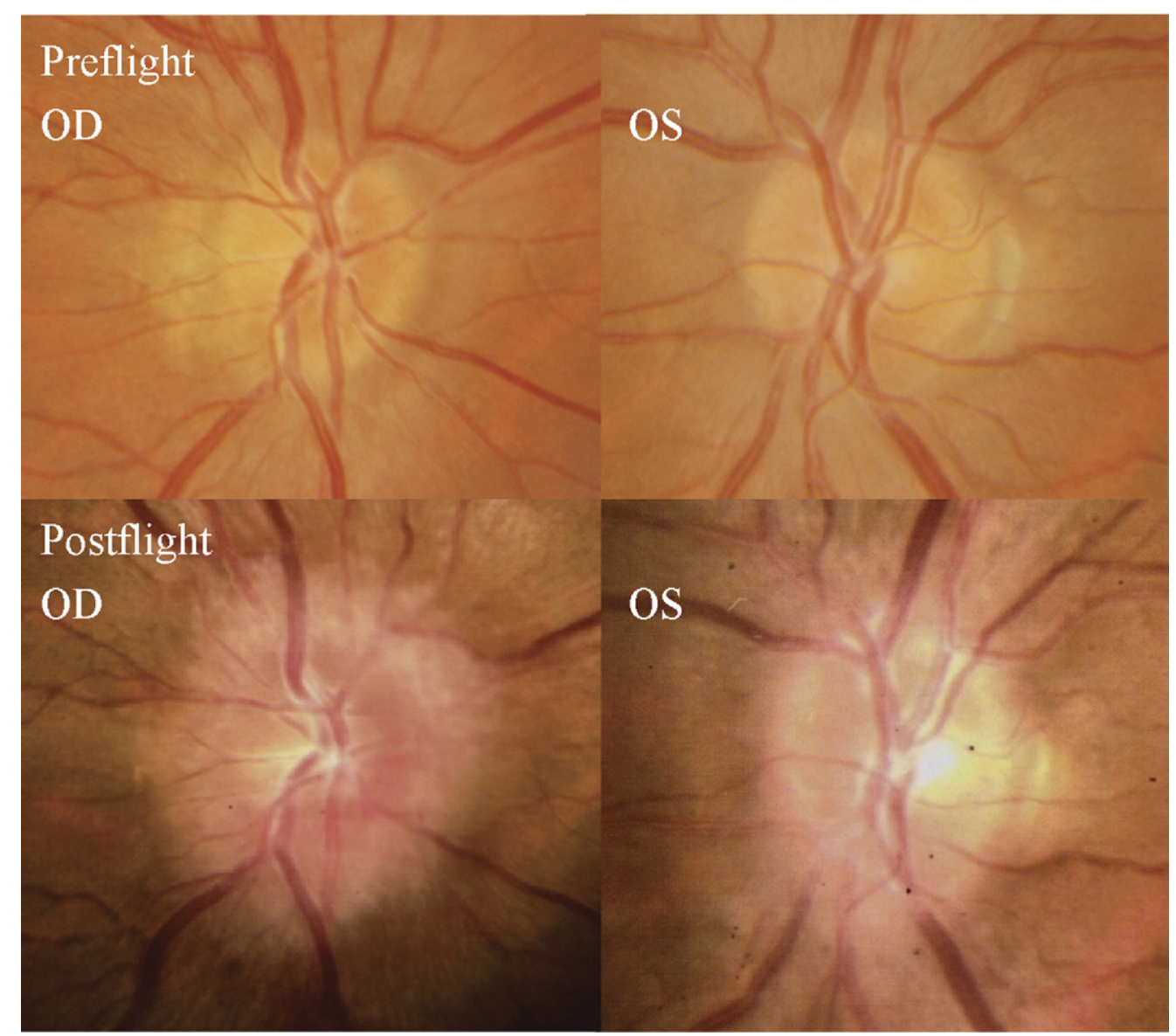

Figure 3. (Top) Preflight images of the right and left optic discs. (Bottom) Postflight images of the right and left optic disc showing grade 3 edema at the right optic disc and Frisén grade 1 edema at the left optic disc. $O D=$ right eye; $O S=$ left eye.

After return to Earth, he noticed that his far vision was clearer through his reading glasses. Twenty-one days after his return to Earth, his visual acuity was correctable to $20 / 20$ both eyes with a cycloplegic refraction of $+2.00-0.50 \times 028$ on the right, and +1.00 sphere on the left. A fundus examination documented mild (grade 1) nasal optic disc edema in the right eye only (Fig 10; available online at http://aaojournal.org). There was no evidence of disc edema in the left eye. An MRI of the brain and orbits, performed 46 days after return, revealed bilateral flattening of the posterior globe, right greater than left, and a mildly distended right ON sheath. Forty-eight days after return to Earth, his cycloplegic refraction was +1.50 sphere on the right and +0.75 sphere on the left. He never experienced losses in subjective best-corrected acuity, color vision, or stereopsis. Fundus examination and OCT performed at this time documented mild disc edema (right eye, grade 1) and a CWS in the left eye 2 disc diameters superior temporal to the disc, just inside the superior arcade. Although no choroidal folds were visible by ophthalmoscopy in either eye, mild choroidal folds were noted in the right eye by OCT (Fig 11; available online at http://aaojournal.org). An LP was not performed.

\section{Case 7}

Preflight cycloplegic refraction was +1.25 sphere both eyes, correctable in each eye to $20 / 15$ with a reading add of +1.75 . His preflight dilated eye examination and fundus photos were normal.
During the mission, he took promethazine $25 \mathrm{mg}$ by mouth on day 1 of the mission and $12.5 \mathrm{mg}$ on day 2 to treat symptoms of space adaptation syndrome. While in orbit, he took atorvastatin $40 \mathrm{mg}$ every day, vitamin D $50000 \mathrm{IU} / \mathrm{month}$, and $800 \mathrm{mg}$ ibuprofen as needed. Approximately 2 months into the mission he reported a progressive decrease in his near and far acuity in both eyes, which persisted for the remainder of the mission. At approximately 3 to 4 months into the 6-month mission, he noticed that his normal "Earth" prescription progressive glasses were no longer strong enough for near tasks at which time he began using his stronger "Space Anticipation Glasses" (+1.25 D more plus). He never complained of transient visual obscurations, headaches, diplopia, pulsatile tinnitus, or vision changes during eye movement. The ISS cabin pressure, carbon dioxide, and oxygen levels were reported to be at normal operating levels during the mission. He was not exposed to any toxic substances.

Three days after his return to Earth, his visual acuity was correctable to $20 / 20$ both eyes with a cycloplegic refraction of +2.75 sphere on the right, and +2.50 sphere on the left. He never experienced losses in subjective best-corrected acuity, color vision, or stereopsis. A fundus examination revealed mild bilateral optic disc edema (grade 1), and choroidal folds (Fig 12; available online at http://aaojournal.org; Figs 13 and 14). On OCT, optic disc edema and chorioretinal folds were confirmed (Fig 15). An MRI of the brain and orbits performed 6 days postflight documented bilateral flattening of the posterior globes, distended ON sheaths, and papilledema. Twelve days after return to Earth, LP 

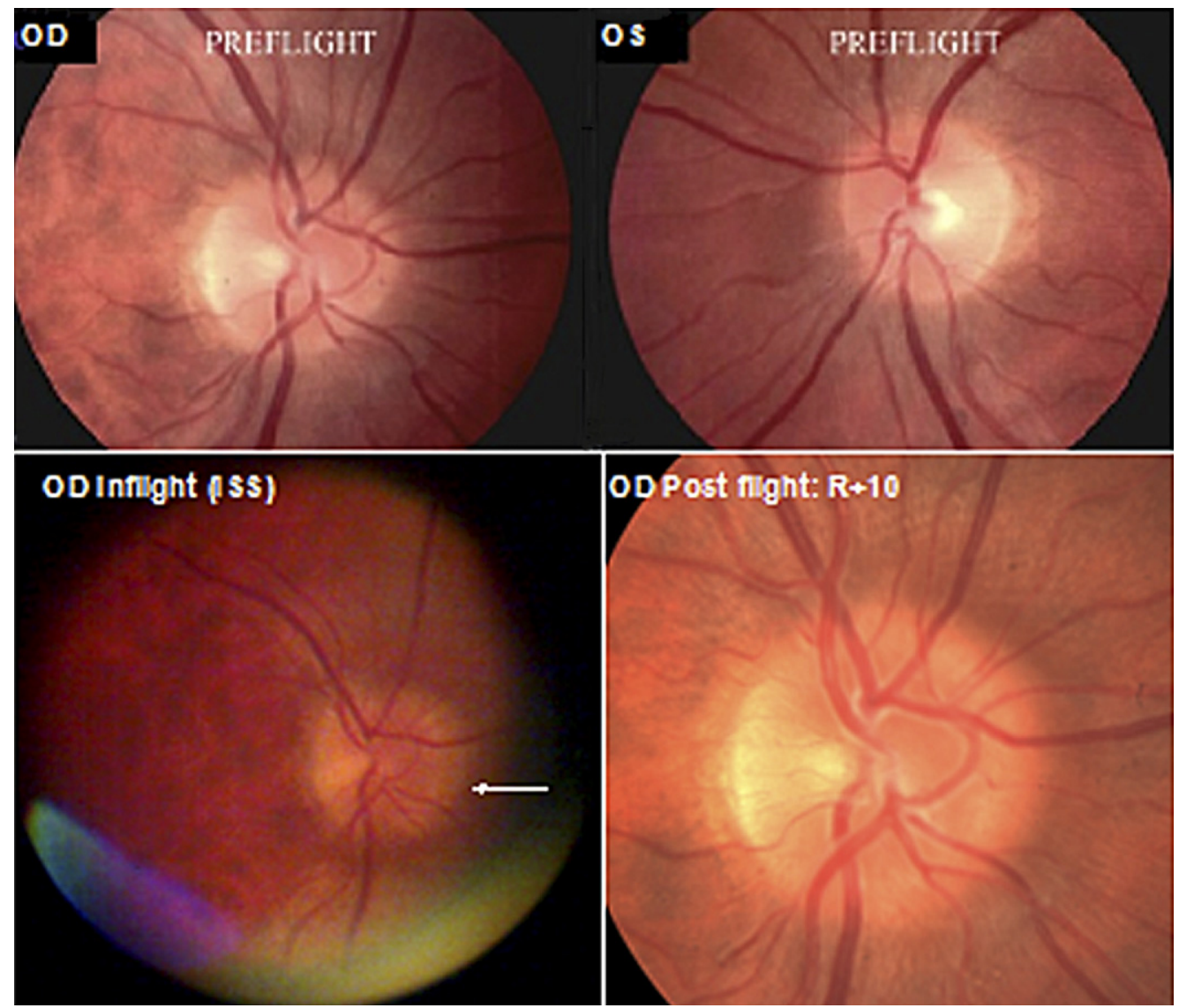

Figure 6. (Top) Preflight images of the right and left posterior pole. (Bottom left) In-flight (International Space Station) photography of the right optic disc obtained by remote guidance showing a "C" halo associated with Frisén grade 1 edema. (Bottom right) Postflight return to Earth +10 days $(\mathrm{R}+10$ ) of the right optic disc shows slightly greater degree of edema inferior-nasal. $\mathrm{OD}=$ right eye; $\mathrm{OS}=$ left eye.

documented an elevated opening pressure of $28 \mathrm{~cm} \mathrm{H}_{2} \mathrm{O}$ with normal CSF composition. A mild degradation in uncorrected near visual acuity and a mild hyperopic shift was documented on this astronaut after a previous short-duration Space Shuttle mission several years before his long-duration mission. His post-Space Shuttle, short-duration flight eye examination was normal with no evidence of disc edema or choroidal folds. At that time, MRI and OCT were not performed postflight. His preflight long-duration OCT raster scans showed what could be evidence of residual choroidal folds from his prior short-duration mission (Fig 15).

\section{Discussion}

In this report, we have described the development of ophthalmic findings in astronauts after long-duration space flight. Although the etiology of these findings remains unknown we propose that one of several mechanisms, or a combination thereof, may best explain our observations. The first possible explanation is that the findings we describe resulted from increased ICP brought about by prolonged microgravity exposure. Numerous authors have described optic disc edema, globe flattening, choroidal folds, and a hyperopic shift in a terrestrial environment, which were thought to be part of the well-defined but still idiopathic syndrome of idiopathic intracranial hypertension
(IIH). ${ }^{1-12}$ Several reports have described the ultrasonography, OCT, MRI and computed tomography findings in IIH that include flattening of the posterior globe and enlargement of the subarachnoid space (SAS) around the ON sheath. ${ }^{3-5,8,10,13}$ The elevated subarachnoid pressure, caused by intracranial hypertension, is thought to be directly transmitted from the intracranial compartment to the intraorbital compartment through the perioptic SAS. ${ }^{8,11}$ This results in distension of the ON sheaths and stasis of axoplasmic flow resulting in axonal swelling and visible disc edema. ${ }^{8,12}$ Elevated intrasheath pressure is thought to cause the subarachnoid compartment to exert an anterior force that indents the posterior sclera resulting in posterior globe flattening, redundancy and folding of the choroid, and axial shortening. The disc edema, posterior globe flattening, choroidal folds, and hyperopic shift seen in cases 2, 4, 6, and 7 seem to be consistent with this description. Case 4 is particularly demonstrative (Fig 8). Additionally, we measured elevated LP opening pressures of 28.5 and $28 \mathrm{~cm} \mathrm{H}_{2} \mathrm{O}$ at 57 days and 12 days, respectively, after returning to Earth. Although these opening pressures were only mildly elevated, they could represent the downslope of a pressure spike that may have existed during microgravity exposure.

The specific mechanism of an IIH-like syndrome in extended microgravity may involve a rise in cephalad ve- 


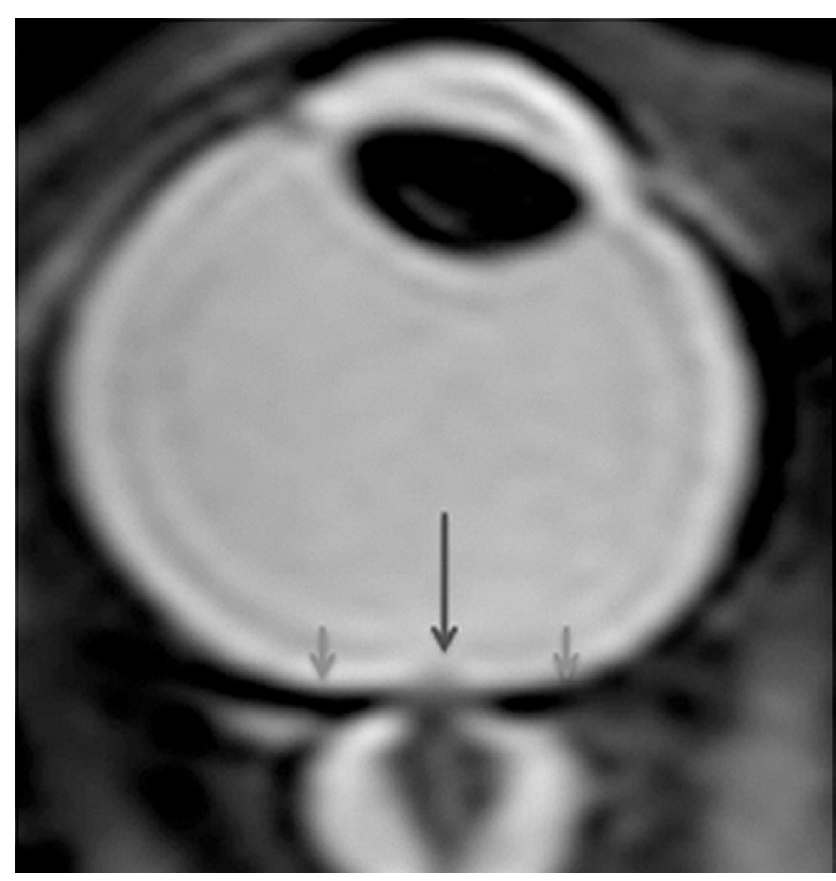

Figure 8. Postflight axial T2 (3T magnetic resonance imaging) showing the flattening of the posterior aspect of the right globe (small arrows) and papilledema (central large arrow) consistent with the optic nerve photography and optical coherence tomography data. Note the marked distension of the optic nerve sheath, which is consistent with congestion seen at the level of the optic disc.

nous pressure brought about by microgravity fluid shifts. Head-down and microgravity studies document that cerebral arterial diameter and blood flow velocity are autoregulated and do not change significantly during space flight. ${ }^{14,15}$ In contrast, microgravity fluid shifts are welldocumented to cause jugular vein distension, ${ }^{16-19}$ which suggests that cerebral venous congestion may be present in the microgravity environment. The classical view of ICP regulation assumes that $\mathrm{CSF}$ is largely produced in the choroid plexus and drainage depends on the pressure difference between the CSF and the venous system. ${ }^{20-22}$ In this scenario, venous stasis in the head and neck, produced by cephalad fluid shifts, may cause an impairment of CSF outflow as well as cerebral venous congestion, both of which would presumably lead to a rise in ICP. ${ }^{23}$ An alternate hypothesis suggests that CSF formation and absorption are due to a balance between hyperosmolar plasma in high pressure capillaries, and the subsequent absorption of the formed hypo-osmolar interstitial fluid by the low-pressure venules that are in anatomic proximity to the high-pressure capillaries. $^{24}$ According to this hypothesis, CSF is permanently produced and absorbed in the entire CSF system. If this is true, the microgravity environment may cause interstitial venous stasis at the level of low pressure CSF venules and a subsequent decrease in the osmotic drive toward absorption, resulting in increased ICP. Regardless of the specific mechanism, perhaps in some anatomically predisposed astronauts, increased venous congestion causes a rise in CSF pressure of sufficient magnitude to produce the changes described.
There are significant arguments against increased ICP being the sole etiology in the cases we describe. Although we documented only 2 cases with a clearly elevated LP opening pressure, our findings in 2 additional patients of disc edema, ON sheath thickening, and posterior globe flattening are suggestive of a rise in ICP. However, several factors may speak against a rise in ICP as a universal cause of all such findings in the astronaut population. First, this supposition is largely based on the similarity of our astronaut's fundi to those of IIH patients observed in a terrestrial setting. However, the disease process of these IIH patients arose on Earth, where microgravity and cephalad fluid shifts played no role in the creation of disc edema, so the specific etiology cannot be determined on the basis of fundus examination alone. Second, none of our patients with disc edema, globe flattening, choroidal folds, or hyperopic shifts presented with chronic headaches, diplopia, transient visual obscurations, pulse-synchronous tinnitus, or other clinical symptoms suggestive of elevated ICP. Headache is experienced by $>90 \%$ of IIH patients, transient visual obscurations in $68 \%$, and sixth nerve palsy in $30 \% .^{4,25}$ This consistent lack of symptoms would be unusual with an ICP of sufficient magnitude to produce clinically recognizable disc edema. Third, because no LP was performed in the ISS during the missions, we have no direct confirmatory evidence that a rise in ICP ever existed during space flight. Fourth, the prominent degree of globe flattening, disc edema, widened ON sheaths, and choroidal folds documented in these astronauts are clearly out of proportion to the relatively unimpressive ICP measurements. Therefore, etiologies other than a rise in ICP should be considered.

The second possible explanation of our findings is that the ON head edema is the result of localized events occurring at the level of the intraorbital ON without a rise in CSF pressure. It has generally been assumed that there is homogeneity of pressure and CSF component concentrations throughout the SAS of the ONs. ${ }^{26}$ However, impaired exchange of fluid between the intracranial CSF and that in the SAS of the ON has been proposed as a possible mechanism to explain persistent papilledema and visual loss in patients with IIH despite a functioning lumboperitoneal shunt. ${ }^{27-29}$ As mentioned, a new hypothesis suggests that CSF is permanently produced and absorbed in the entire CSF system as a consequence of filtration and reabsorption of water volume through the capillary walls into the surrounding brain tissue. $^{24}$ This implies that the CSF exchange between each portion of the CSF system and the surrounding tissue may depend on pathophysiologic conditions that predominate within those compartments. ${ }^{24}$ Also, animal studies document lymphatic drainage of CSF via the ethmoidal lymphatics. ${ }^{30}$ Lymphatics in the dura of the human ON have also been proposed as a CSF outflow pathway. $^{27}$ If such lymphatic drainage systems exist, perhaps microgravity exposure leads to lymph stasis, which could also be a contributing factor for an increase in $\mathrm{ON}$ sheath pressures. The unique cul de sac-like anatomic connection between the intracranial SAS and the SAS of the ON may also create an environment that could be impacted by microgravity fluid changes. As noted by Killer et al, ${ }^{27}$ it is difficult to explain the 


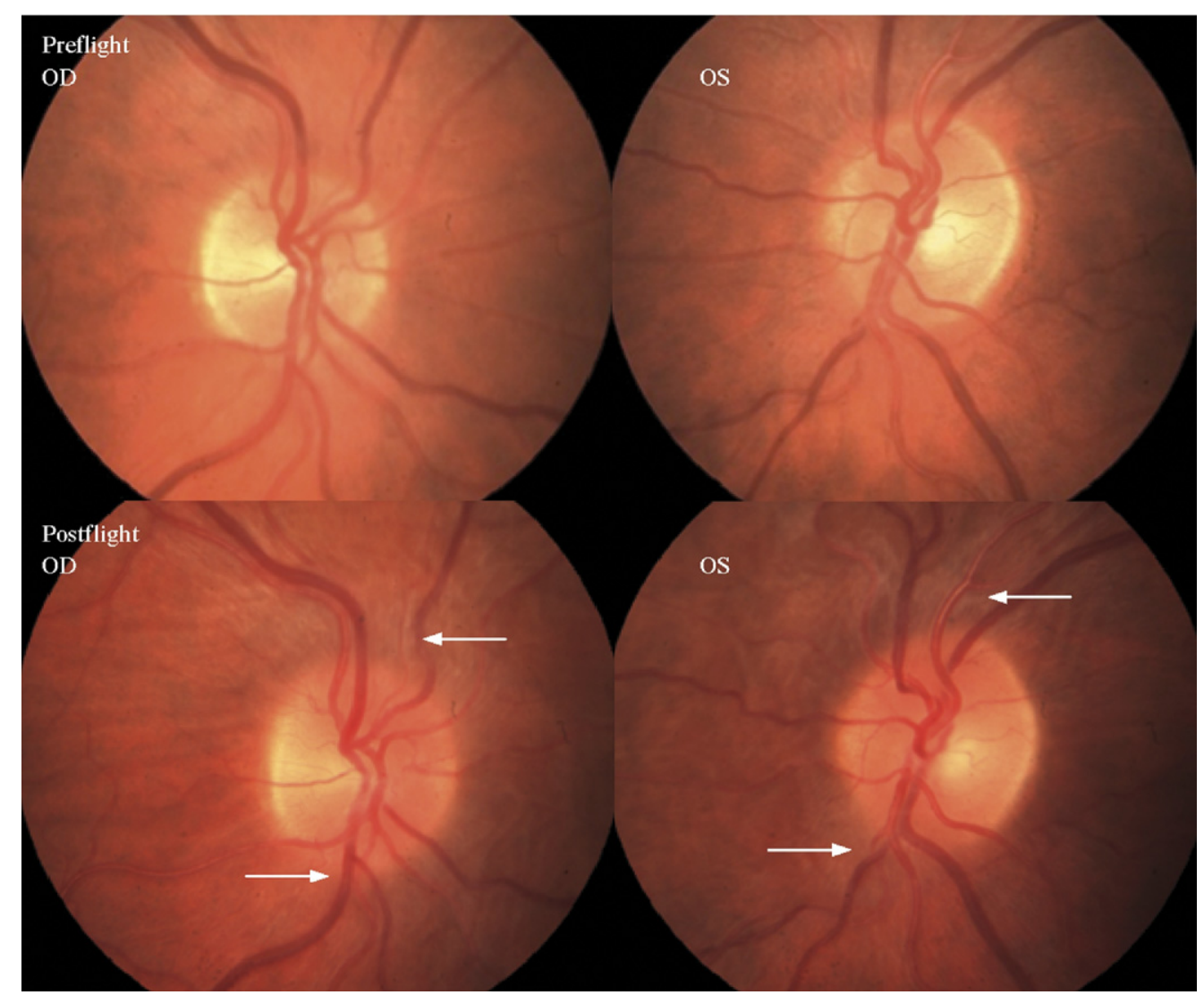

Figure 13. (Top) Preflight images of the right and left optic discs. (Bottom) Postflight images of the optic nerve head showing in more detail the extent of the edematous optic disc margins and glutting of the superior and inferior nerve fiber layer axons OD and OS (arrows). OD = right eye; OS = left eye.

hydrodynamics of how cranial CSF that enters the SAS of the ON would change its direction of flow against an intracranial volume gradient to exit the ON sheath. This analysis suggests a rather fragile flow equilibrium within the ON sheath, even in normal subjects. It is self-evident that under normal 1-G physiologic conditions, CSF secretion, flow, and absorption within the ON sheath are balanced. Regardless of the specific origin of CSF production and drainage, long-standing microgravity fluid shifts may bring about alterations in CSF flow dynamics in the intraorbital portion of the SAS, such that CSF enters SAS, but outflow may be slightly impeded. Thus, under prolonged microgravity conditions, CSF in the SAS of the ON may gradually become partially or completely sequestered, producing a type of ON compartment syndrome that may result in varying degrees of disc edema and/or globe flattening, even in the absence of elevated ICP.

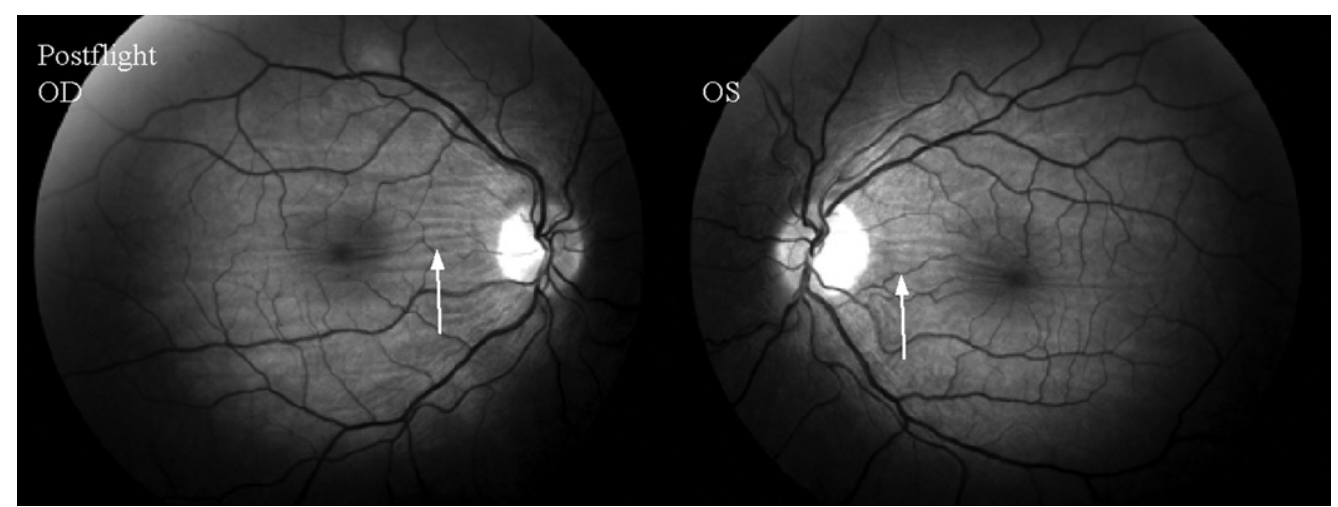

Figure 14. Postflight at 'return to Earth +39 days' $(\mathrm{R}+39)$ red-free fundus photography highlighting the extent of the horizontal choroidal and retinal folds in the posterior fundus (OD>OS). $O D=$ right eye, $O S=$ left eye. 

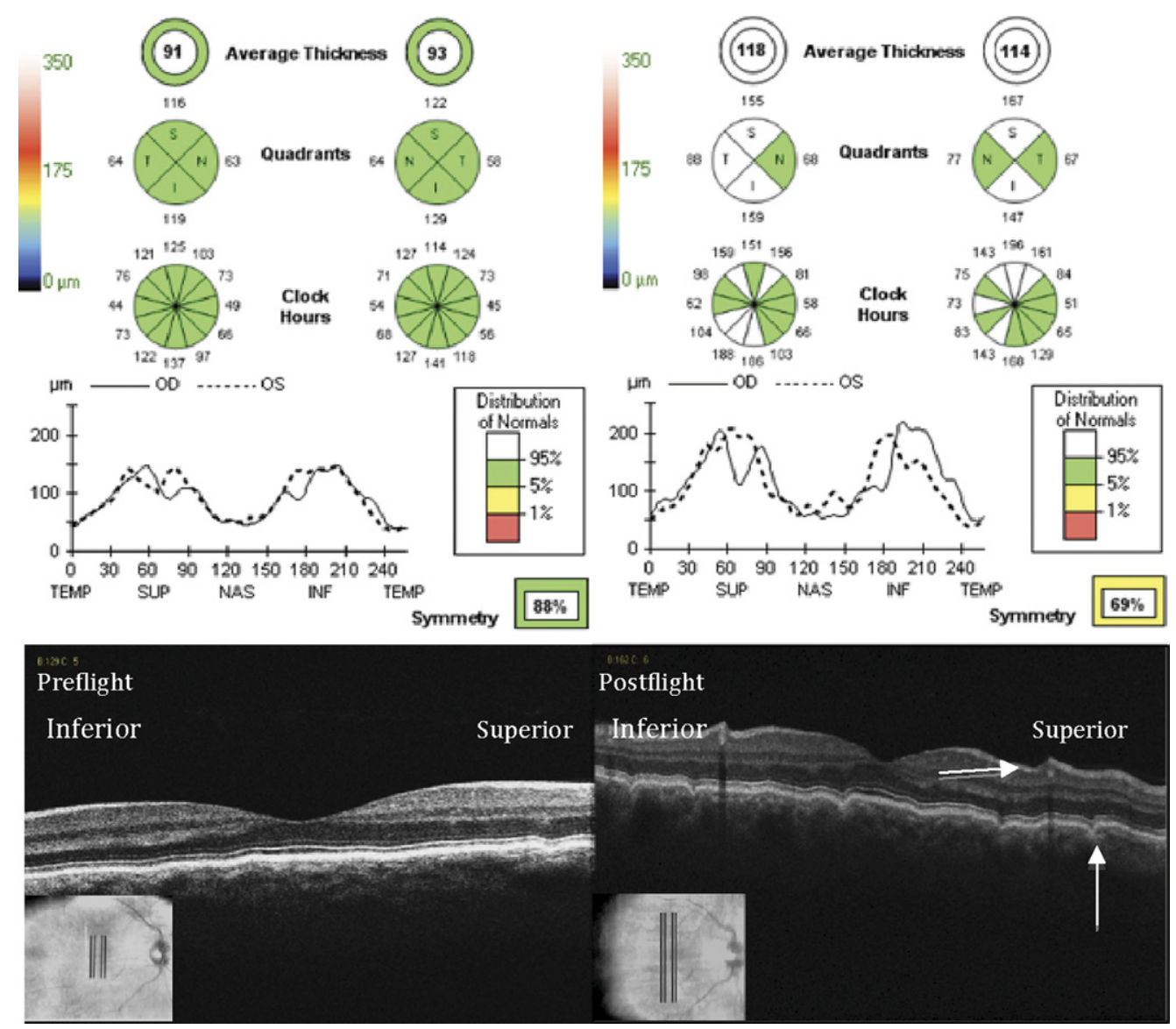

Figure 15. (Top) Preflight (left) and postflight (right) Cirrus spectral domain optical coherence tomography (SD-OCT) of the peripapillary nerve fiber layer (NFL) thickness maps and 'TSNIT' thickness graph for the right and left eyes. An $\sim 50$-micron thickness increase at the peak of the superior and inferior NFL poles. (Bottom) Preflight and postflight Cirrus SD-OCT vertical high-definition raster scan through the macula of the right eye showing the choroidal/retinal folds (arrows). INF = inferior; NAS = nasal; OD = right eye; OS = left eye; TEMP = temporal; SUP = superior; TSNIT = temporal, superior, nasal, inferior, temporal (NFL sections).

A third possible etiology for our findings is ocular hypotony. It is well established that there is an initial spike in intraocular pressure (IOP) on exposure to microgravity followed by a decrease in IOP over a period of days. ${ }^{31}$ Unfortunately, no long-term studies of IOP have ever been done in microgravity to document further trends. Head-down bed rest studies suggest that the initial spike in IOP is followed by a leveling ${ }^{32}$ or lowering ${ }^{33,34}$ of IOP over a period of days. The initial spike in IOP is thought to occur as a result of choroidal expansion brought about by cephalad fluid shifts. ${ }^{32,35}$ It is hypothesized that the decrease in IOP after the initial spike may be the result of a compensatory decrease in aqueous volume. ${ }^{32}$ Although no long-term IOP data exists from space flight, a low IOP on Earth immediately after space missions has been documented as far back as the Apollo Program. ${ }^{36}$ Thus, in-flight, postflight, and head-down studies suggest the possibility that a lowering of IOP may occur during extended microgravity exposure. Although the degree of IOP change is unknown, perhaps in some individuals the IOP can decrease to the point where pathologic changes become evident. Ocular hypotony, generally defined as an IOP of $<6.5 \mathrm{mmHg}$, is welldocumented to cause disc edema, posterior globe flattening, choroidal folds, and a hyperopic shift very similar to some of our observed changes. ${ }^{37,38}$

The etiology of the hyperopic shift, more commonly observed during extended microgravity exposure, has been touched on but merits further discussion. In postflight questionnaires completed by approximately 300 NASA astronauts, nearly $50 \%$ of astronauts on long-duration ISS missions and $23 \%$ on short-duration shuttle missions have complained of degradation in near vision. A postflight refraction change (i.e., hyperopic shift) was documented in $11 \%$ and $34 \%$ of astronauts after short and long-duration missions, respectively (Table 2). This is more clinically apparent in older astronauts with decreased accommodation. In fact, NASA astronauts over the age of 40 are routinely offered the use of plus lens "Space Anticipation Glasses" preflight should they experience a hyperopic shift during the mission. As noted, this shift is usually reported after weeks or months in space and less often during short flights. The onset of the hyperopic shift seems to be gradual, variable in magnitude, and has been reported to persist in the $1-G$ environment for months to years after return to Earth. Although 1 long-duration, head-down study documented a decrease in near visual acuity after 4 to 5 days of 


\section{Mader et al - Eye Changes after Long-duration Space Flight}

head-down tilt, ${ }^{39}$ another similar study noted no visual changes. ${ }^{40}$ Several hypotheses may be offered to explain this hyperopic shift. In theory, variable increases in ICP with resultant increases in subarachnoid pressure could cause corresponding degrees of posterior globe flattening. We have no data to suggest that disc edema and globe flattening are common findings in astronauts. The normal aging process in those $>40$ may lead to a progressive shortening of the axial length that could theoretically account for these changes. ${ }^{41}$ It would be difficult to explain why this process would be exacerbated by exposure to microgravity. Changes in corneal refractive power after exposure to changes in atmospheric pressure and oxygen partial pressure could be a possible mechanism. However, considerable research has proven that normal, nonrefractive surgery corneas are not subject to refractive changes during exposure to changing environmental conditions. ${ }^{42-44}$ It is also possible, although unlikely, that the fluid shifts within the eye could result in lenticular changes, which may lead to alterations in refractive error.

Choroidal expansion may thus at least partially account for the hyperopic shifts we describe. The spongy, highly vascular choroid is normally approximately $0.3 \mathrm{~mm}$ in thickness, is drained by the vortex veins, and is likely sensitive to impeded outflow produced by microgravity. Perhaps not all of the hyperopic shifts we describe were caused by indentation of the globe from an elevated subarachnoid pressure but occurred through a different mechanism. Choroidal volume changes in microgravity may be responsible for the abrupt increase in IOP (within $30 \mathrm{sec}$ onds) in orbital and $\mathrm{KC}-135$ parabolic flights as well as head-down studies. ${ }^{31,32,35}$ Because ocular liquids within the eye are incompressible, the IOP depends on the intraocular fluid volume and the rather rigid elastic properties of the cornea and sclera. Therefore, a bolus of blood introduced into the eye will initially cause a rise in IOP. ${ }^{45}$ Although increased episcleral venous pressure and orbital congestion may add to the rise in IOP during microgravity exposure, it would not explain the sudden IOP increase. ${ }^{32}$ It is hypothesized that cephalad fluid shifts cause venous congestion in the neck and head that lead to a rise in vortex vein pressure. ${ }^{32,35}$ This may cause decreased choroidal drainage and lead to a relatively stagnant pooling of blood in the choroid. ${ }^{46}$ This process could result in a small but abrupt increase in choroidal volume and may account for the sudden rise in IOP noted during microgravity exposure. The wide spectrum of degree of hyperopic shift would imply that there is some variation in the choroidal anatomy and some are more susceptible to choroidal swelling than others. Choroidal vasculature alterations have been reported in highly myopic eyes ${ }^{47}$ but could also exist in the general population. Choroidal engorgement over time may push the macula forward slightly, thus shortening the distance between the macula and the lens. A $0.33-\mathrm{mm}$ anterior displacement at the macula would lead to a 1-D shift toward hyperopia. This choroidal pooling may gradually expand the delicate collagen lamella of the choroid beyond its normal anatomic structural boundaries such that the choroid becomes permanently distended even on return to the 1-G environment and in the presence of normal venous back- pressure. Our case 1, wherein the choroidal folds were well-documented to be present several years after the mission with no evidence of disc edema, may demonstrate this point. Choroidal folds have also been documented to exist for years on Earth in the absence of increased ICP. ${ }^{7}$ Therefore, in a space traveler there might not be a fixed distance between the retina and the lens, as there is on Earth. As seen in Table 2, data from postflight questionnaires completed by approximately 300 astronauts after their short- and longduration space missions showed that approximately $23 \%$ of the short-duration and $48 \%$ of the long-duration mission astronauts complained of near vision difficulties. It may be that choroidal expansion and presumably a commensurate hyperopic shift may be quite common during space flight and may exist for months to years after return to Earth.

Although a degree of choroidal expansion is likely present in any space traveler some individuals may be anatomically predisposed to the formation of visible choroidal folds. Choroidal folds may be produced by the mechanical indentation of the posterior globe from a rise in subarachnoid pressure. Newell ${ }^{48}$ hypothesized that visible choroid folds may occur as a result of a combination of variable anatomic attachments of the choroid to Bruch's membrane and some factor that causes congestion in the choriocapillaris. When choroidal expansion occurs and this attachment is not present, the pigment epithelium slips easily over the choriocapillaris, the folds are not produced, and the fundus has a smooth appearance despite choroidal thickening. Alternatively, choroidal congestion combined with adhesions prevents this slipping and leads to the classic striations of choroidal folds. The light lines, seen in ophthalmoscopy, correspond to the crests of the folds where the retinal pigment epithelium is attenuated. The dark lines correspond with the troughs of the folds where there is compaction of the retinal pigment epithelium. Thus, choroidal expansion may have a different clinical appearance depending on the microanatomy of the individual astronaut. Although prominent choroidal expansion is rather unusual on Earth, our report suggests that it may be common on exposure to extended microgravity. Therefore, the hyperopic shifts observed in these astronauts may not universally result from a rise in ICP or a drop in IOP. However, they may be the consequence of local fluid changes within the eye and orbit brought about by microgravity exposure.

We also report unilateral CWS in 3 astronauts after exposure to extended microgravity. Only one occurred in conjunction with $\mathrm{ON}$ edema in that eye. Feathery edged infarctions of the surface of the NFL layer, CWS usually occur in the area of the radial peripapillary capillaries. ${ }^{49}$ They are thought to be accumulations of cytoplasmic debris caused by focal obstruction of orthograde and or retrograde axoplasmic transport ${ }^{29}$ and they may leave a permanent retinal defect. ${ }^{50}$ The fundamental lesion causing a CWS is thought to be precapillary arteriolar closure. ${ }^{50,51}$ Although CWS are nonspecific, they are well known to occur in diabetes mellitus, ${ }^{52}$ HIV retinopathy, ${ }^{53}$ Purtscher's retinopathy, ${ }^{54}$ high-altitude retinopathy, ${ }^{55}$ and hypertensive retinopathy. ${ }^{56}$ They are not commonly associated with increased ICP. The etiology of these findings in our astronauts is unknown, but we may assume that these changes are 
somehow related to cephalad fluid shifts during extended space flight. As noted, local, asymmetric microgravity related changes in CSF flow within the intraorbital portion of the ON may lead to a biochemically altered CSF that may cause a metabolic toxicity to the $\mathrm{ON}$ and set the stage for focal arteriolar closure. A similar hypothesis has been previously proposed as a mechanism for other forms of axoplasmic stasis. ${ }^{29}$

In summary, although a definitive etiology is unknown, we hypothesize that venous congestion in the brain and/or eye, brought about by cephalad fluid shifts and perhaps exacerbated by choroidal volume changes, may be a unifying pathologic mechanism to explain our findings. These findings may occur in conjunction with microgravityinduced CSF flow disturbances within the ON sheath. Regardless of specific etiology, the disc edema, globe flattening, choroidal folds, and hyperopic shifts we report may represent parts of a spectrum of ocular and cerebral response to microgravity. Because all symptoms occurred after long-term exposure to microgravity and the disc edema in 2 astronauts was documented by direct observation on board the spacecraft, it would be extremely unlikely that the effects of takeoff, reentry, or landing were involved. Because detailed preflight and postflight dilated retinal examinations with fundus photography and OCT have only been conducted in NASA astronauts over the last 4 years and all cases we report were largely asymptomatic, this suggests that similar cases may have been missed in the past. Recently, NASA has initiated a protocol to acquire prospective preflight, in-flight, and postflight data on all future astronauts to define the exact origin of these potentially harmful ocular changes. These data would include preflight and postflight MRI, OCT, and LPs when appropriate, as well as preflight, in-flight, and postflight IOP measurement, dilated eye examination, ultrasound imaging, cycloplegic refraction, and fundus photography.

Acknowledgments. The authors thank the Lifetime Surveillance of Astronaut Health Program, NASA Johnson Space Center, for their help with statistical and data management.

\section{References}

1. Nettleship E. Peculiar lines in the choroid in a case of postpapillitic atrophy. Trans Ophthalmol Soc U K 1884;4:167-8.

2. Kalina RE, Mills RP. Acquired hyperopia with choroidal folds. Ophthalmology 1980;87:44-50.

3. Lavinsky J, Lavinsky D, Lavinsky F, Frutuoso A. Acquired choroidal folds: a sign of idiopathic intracranial hypertension. Graefes Arch Clin Exp Ophthalmol 2007;245:883-8.

4. Friedman D. Idiopathic intracranial hypertension. Curr Pain Headache Rep 2007;11:62-8.

5. Griebel SR, Kosmorsky GS. Choroidal folds associated with increased intracranial pressure. Am J Ophthalmol 2000;129: 513-6.

6. Sarraf D, Schwartz SD. Bilateral choroidal folds and optic neuropathy: a variant of the crowded disk syndrome? Ophthalmology 2003;110:1047-52.

7. Sharma M, Volpe NJ, Patel T, Kimmel A. Intracranial hypertension associated with acquired hyperopia and choroidal folds. Retina 1999;19:260-2.
8. Jacobson DM. Intracranial hypertension and the syndrome of acquired hyperopia with choroidal folds. J Neuroophthalmol 1995; 15:178-85.

9. Cassidy LM, Sanders MD. Choroidal folds and papilloedema. Br J Ophthalmol 1999;83:1139-43.

10. Dailey RA, Mills RP, Stimac GK, et al. The natural history and CT appearance of acquired hyperopia with choroidal folds. Ophthalmology 1986;93:1336-42.

11. Liu D, Kahn M. Measurement and relationship of subarachnoid pressure of the optic nerve to intracranial pressures in fresh cadavers. Am J Ophthalmol 1993;116:548-56.

12. Tso MO, Hayreh SS. Optic disc edema in raised intracranial pressure. IV. Axoplasmic transport in experimental papilledema. Arch Ophthalmol 1977;95:1458-62.

13. Guiffre G, Distefano MG. Optical coherence tomography of chorioretinal and choroidal folds. Acta Ophthalmol Scand 2007;85:333-6.

14. Iwasaki K, Levine BD, Zhang R, et al. Human cerebral autoregulation before, during and after spaceflight. J Physiol 2007; 579:799-810.

15. Frey MA, Mader TH, Bagian JP, et al. Cerebral blood velocity and other cardiovascular responses to 2 days of head-down tilt. J Appl Physiol 1993;74:319-25.

16. Thornton WE, Hoffler GW, Rummel JA. Anthropometric changes and fluid shifts. In: Johnston R, Dietlein L, eds. Biomedical Results from Skylab. Washington, DC: Scientific and Technical Information Office, NASA; 1977. Available at: http://lsda.jsc.nasa.gov/books/skylab//Ch32.htm. Accessed May 29, 2011.

17. Arbeille P, Fomina G, Roumy J, et al. Adaptation of the left heart, cerebral and femoral arteries, and jugular and femoral veins during short- and long-term head-down tilt and space flights. Eur J Appl Physiol 2001;86:157-68.

18. Harris BA Jr, Billica RD, Bishop SL, et al. Physical examination during space flight. Mayo Clin Proc 1997;72:301-8.

19. Herault S, Fomina G, Alferova I, et al. Cardiac, arterial and venous adaptation to weightlessness during 6-month MIR spaceflights with and without thigh cuffs (bracelets). Eur J Appl Physiol 2000;81:384-90.

20. Davson H, Domer FR, Hollingsworth JR. The mechanism of drainage of the cerebrospinal fluid. Brain 1973;96:329-36.

21. Andersson N, Malm J, Eklund A. Dependency of cerebrospinal fluid outflow resistance on intracranial pressure. J Neurosurg 2008;109:918-22.

22. Alperin N, Lee SH, Mazda M, et al. Evidence for the importance of extracranial venous flow in patients with idiopathic intracranial hypertension (IIH). Acta Neurochir Suppl 2005; 95:129-32.

23. Kapoor KG, Katz SE, Grzybowski DM, Lubow M. Cerebrospinal fluid outflow: an evolving perspective. Brain Res Bull 2008;77:327-34.

24. Oreskovic D, Klarica M. The formation of cerebrospinal fluid: nearly a hundred years of interpretations and misinterpretations. Brain Res Rev 2010;64:241-62.

25. Giuseffi V, Wall M, Siegel PZ, Rojas PB. Symptoms and disease associations in idiopathic intracranial hypertension (pseudotumor cerebri): a case-control study. Neurology 1991; 41:239-44.

26. Killer HE, Jaggi GP, Flammer J, et al. The optic nerve: a new window into cerebrospinal fluid composition? Brain 2006; 129:1027-30.

27. Killer HE, Jaggi GP, Flammer J, et al. Cerebrospinal fluid dynamics between the intracranial and the subarachnoid space of the optic nerve. Is it always bidirectional? Brain 2007;130: 514-20. 


\section{Mader et al - Eye Changes after Long-duration Space Flight}

28. Kelman SE, Sergott RC, Cioffi GA, et al. Modified optic nerve decompression in patients with functioning lumboperitoneal shunts and progressive visual loss. Ophthalmology 1991; 98:1449-53.

29. Killer HE, Jaggi GP, Miller NR. Papilledema revisited: is its pathophysiology really understood? Clin Experiment Ophthalmol 2009;37:444-7.

30. Johnston M, Zakharov A, Koh L, Armstrong D. Subarachnoid injection of Microfil reveals connections between cerebrospinal fluid and nasal lymphatics in the non-human primate. Neuropathol Appl Neurobiol 2005;31:632-40.

31. Draeger J, Wirt H, Schwartz R. Tonometry under microgravity conditions. In: Sahm PR, Jansen R, Keller MH, eds. Proceedings of the Norderney Symposium on Scientific Results of the German Spacelab Mission: D1, Nordenerney, Germany, August 27-29, 1986. Koln, Germany: Wissenschaftliche Projektführung DI c/o DFVLR; 1987;503-9.

32. Mader TH, Taylor GR, Hunter N, et al. Intraocular pressure, retinal vascular, and visual acuity changes during 48 hours of 10 degrees head-down tilt. Aviat Space Environ Med 1990; 61:810-3.

33. Chiquet C, Custaud MA, Le Traon AP, et al. Changes in intraocular pressure during prolonged (7-day) head-down tilt bedrest. J Glaucoma 2003;12:204-8.

34. Drozdova NT, Grishin EP. State of the visual analyzer during hypokinesia [in Russian]. Kosm Biol Med 1972;6:46-9.

35. Mader TH, Gibson CR, Caputo M, et al. Intraocular pressure and retinal vascular changes during transient exposure to microgravity. Am J Ophthalmol 1993;115:347-50.

36. Nicogossian AE, Parker JF Jr. Space Physiology and Medicine. Washington, DC: NASA, Technical Information Branch; 1982;158. NASA SP-447.

37. Costa VP, Arcieri ES. Hypotony maculopathy. Acta Ophthalmol Scand 2007;85:586-97.

38. Westfall AC, Ng JD, Samples JR, Weissman JL. In reply to: Brodsky MC. Flattening of the posterior sclera: hypotony or elevated intracranial pressure [letter]? Am J Ophthalmol 2004; 138:511-2.

39. Drozdova NT, Nesterenko ON. State of the visual analyzer during hypodynamia. In: Genin AM, ed. Prolonged Limitation of Motility and its Influence on Human Organism. Washington, DC: NASA; 1970:192-5. Problems of Space Biology. vol. 13. NASA TT F-639.

40. Mekjavic PJ, Eiken O, Mekjavic IB. Visual function after prolonged bed rest. J Gravit Physiol 2002;9:P31-2.
41. Grosvenor T. Reduction in axial length with age: an emmetropizing mechanism for the adult eye? Am J Optom Physiol Opt 1987;64:657-63.

42. Mader TH, White LJ. Refractive changes at extreme altitude after radial keratotomy. Am J Ophthalmol 1995;119:733-7.

43. Mader TH, Blanton CL, Gilbert BN, et al. Refractive changes during 72-hour exposure to altitude after refractive surgery. Ophthalmology 1996;103:1188-95.

44. Winkle RK, Mader TH, Parmley VC, et al. The etiology of refractive changes at high altitude following radial keratotomy: hypoxia versus hypobaria. Ophthalmology 1998;105:282-6.

45. Silver DM, Geyer O. Pressure-volume relation for the living human eye. Curr Eye Res 2000;20:115-20.

46. Kergoat H, Lovasik JV. Seven-degree head-down tilt reduces choroidal pulsatile ocular blood flow. Aviat Space Environ Med 2005;76:930-4.

47. Moriyama M, Ohno-Matsui K, Futagami S, et al. Morphology and long-term changes of choroidal vascular structure in highly myopic eyes with and without posterior staphyloma. Ophthalmology 2007; 114:1755-62.

48. Newell FW. Choroidal folds. The seventh Harry Searls Gradle Memorial lecture. Am J Ophthalmol 1973;75:930-42.

49. Henkind P. Radial peripapillary capillaries of the retina. I. Anatomy: human and comparative. Br J Ophthalmol 1967;51: 115-23.

50. Gomez ML, Mojana F, Bartsch D, Freeman WR. Imaging of long-term retinal damage after resolved cotton wool spots. Ophthalmology 2009;116:2407-14.

51. Schmidt D. The mystery of cotton-wool spots: a review of recent and historical descriptions. Eur J Med Res 2008;13: 231-66.

52. UK Prospective Diabetes Study (UKPDS) Group. Risks of progression of retinopathy and vision loss related to tight blood pressure control in type 2 diabetes mellitus: UKPDS 69. Arch Ophthalmol 2004;122:1631-40.

53. Berrey MM, Shea T, Corey L. Cotton-wool spots in primary HIV infection [letter]. J Acquir Immune Defic Syndr Hum Retrovirol 1998;19:197-8.

54. Agrawal A, McKibbin M. Purtscher's retinopathy: epidemiology, clinical features and outcome. Br J Ophthalmol 2007; 91:1456-9.

55. Morris DS, Somner J, Donald MJ, et al. The eye at altitude. Adv Exp Med Biol 2006;588:249-70.

56. Wong TY, McIntosh R. Hypertensive retinopathy signs as risk indicators of cardiovascular morbidity and mortality. Br Med Bull 2005;7374:57-70.

\section{Footnotes and Financial Disclosures}

Originally received: January 28, 2011.

Final revision: June 17, 2011.

Accepted: June 17, 2011.

Available online: August 17, 2011.

Manuscript no. 2011-155.

${ }^{1}$ Department of Ophthalmology, Alaska Native Medical Center, Anchorage, Alaska.

${ }^{2}$ Coastal Eye Associates, Webster, Texas.

${ }^{3}$ University of Houston, University Eye Institute, Houston, Texas.

${ }^{4}$ Department of Diagnostic Imaging and Intervention, University of Texas Health Science Center, Houston, Texas.

${ }^{5}$ Department of Ophthalmology, The Methodist Hospital, Houston, Texas.

${ }^{6}$ NASA Johnson Space Center, Space Medicine, Houston, Texas.

\footnotetext{
${ }^{7}$ Wyle Integrated Science and Engineering, Houston, Texas.

${ }^{8}$ NASA Johnson Space Center, Houston, Texas.

${ }^{9}$ German Aerospace Center, Cologne, Germany.

${ }^{10}$ Crew Medical Support Office, European Space Agency, Cologne, Germany.
}

Some activities related to this report were accomplished while under contract paid by the National Aeronautics and Space Administration.

Financial Disclosure(s):

The authors have no proprietary or commercial interest in any of the materials discussed in this article.

Correspondence: Thomas H. Mader, MD, Department of Ophthalmology, Alaska Native Medical Center, 4315 Diplomacy Drive, Anchorage AK 99508. E-mail: tmader@acsalaska.net 


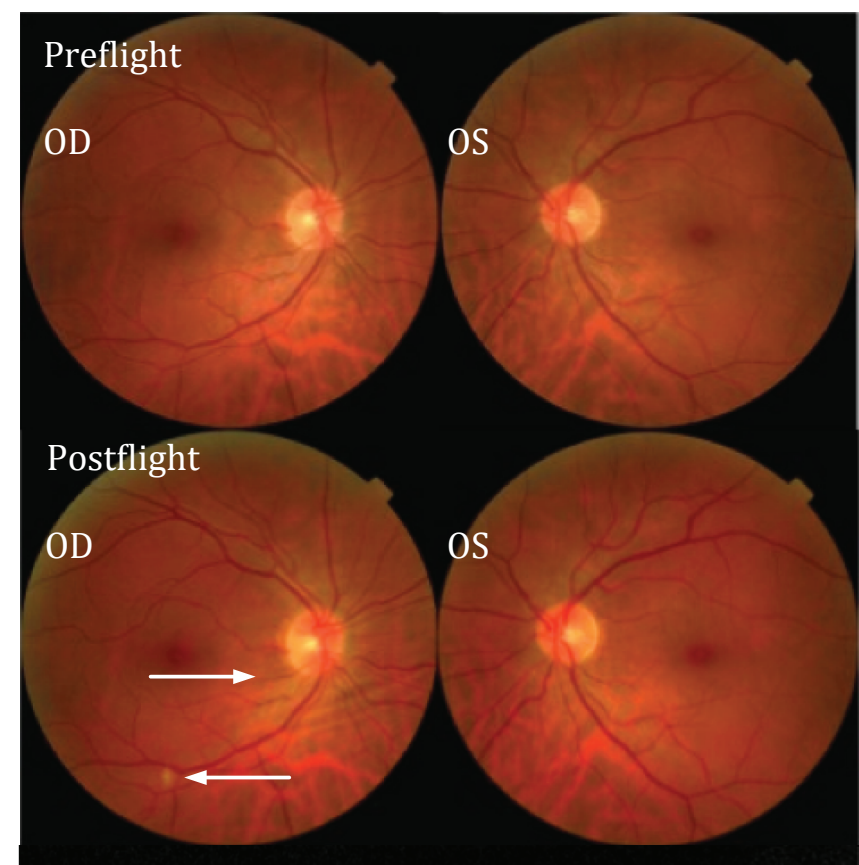

\section{Postflight OD}

\section{Inferior}

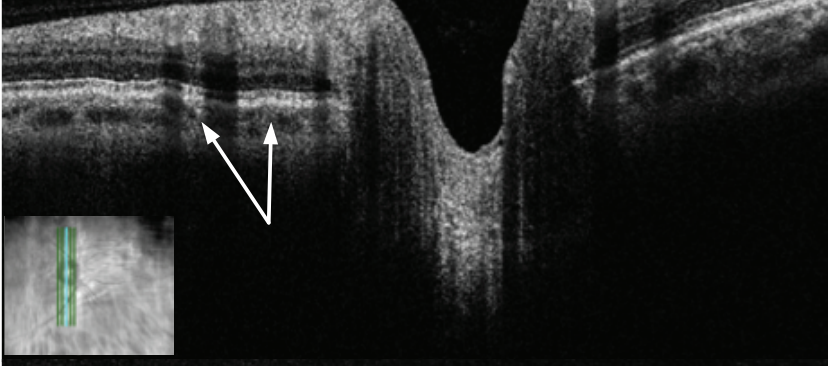

\section{Postflight OS}

\section{Inferior}

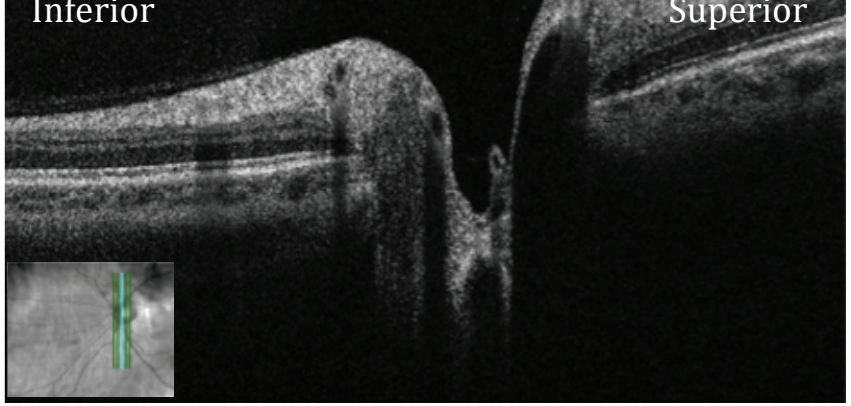

Fig. 1; [Top group; upper row] Preflight fundus images of the right and left posterior pole. [Top group; lower row] Postflight return to Earth +19 days $(\mathrm{R}+19)$ images of the right and left posterior pole showing choroidal folds below the optic disc (top arrow) and a "cotton-wool" spot (bottom arrow) in the inferior arcade of the right eye. Optic disc imaging did not show presence of observable disc edema.

[Bottom group] Postflight return to Earth + greater than 5 year $(\mathrm{R}+>5$ years) spectral domain optical coherence tomography (SD-OCT) images showing the presence and persistence of the choroidal folds (arrows) inferior to the right optic disc. Choroidal folds are now only detectable with SD-OCT. OD=right eye, OS=left eye. 